\title{
Do we have to reconsider the evolutionary emergence of myelin?
}

\author{
Hauke B. Werner* \\ Department of Neurogenetics, Max Planck Institute of Experimental Medicine, Göttingen, Germany \\ ${ }^{*}$ Correspondence: hauke@em.mpg.de \\ Edited by: \\ Lawrence Rajendran, University Zurich, Switzerland
}

Keywords: myelination, saltatory impulse propagation, oligodendrocyte, Schwann cell, genomics, vertebrate evolution, lamprey, myelin basic protein (MBP)

\section{A commentary on}

Sequencing of the sea lamprey (Petromyzon marinus) genome provides insights into vertebrate evolution

by Smith, J. J., Kuraku, S., Holt, C., SaukaSpengler, T., Jiang, N., Campbell, M. S., et al. (2013) Nat. Genet. 45, 415-421. doi: 10.1038/ng.2568

A recent publication (Smith et al., 2013) reported the genome sequence of the sea lamprey (Petromyzon marinus). This dataset allows the exploration of early vertebrate evolution because the lamprey lineage split from that of other vertebrates before the emergence of hinged jaws, the defining feature of jawed vertebrates (gnathostomata, ranging from sharks to humans). Additionally, lamprey axons are not ensheathed by myelin (Bullock et al., 1984), a glial specialization that facilitates the rapid propagation of nerve signals (Hartline and Colman, 2007). It is therefore thought that myelin evolved at about the same time as hinged jaws in now-extinct placoderms, the most ancient group of jawed vertebrates (Zalc et al., 2008). Now, Smith et al. have examined the lamprey genome (Smith et al., 2013) to determine whether or not myelin genes evolutionarily pre-dated jawed vertebrates. Several myelin genes were indeed identified. For that reason, the authors propose the intriguing possibility that myelinating cells may have existed already in non-jawed vertebrates and were subsequently lost in the lamprey lineage. This hypothesis is in disagreement with all previous molecular and morphological analyses.

The evolution of myelin basic protein $(\mathrm{MBP})$ is particularly relevant because
MBP is an abundant structural myelin constituent essential for myelination in the central nervous system (CNS). The fact that MBP had not been traced in species more ancient than gnathostomata (Gould et al., 2005; Nawaz et al., 2013) founded the concept that myelin and MBP emerged at about the same time, probably interrelated. As one key observation, Smith et al. report a segment in the lamprey genome that-if translated into protein-would be $86 \%$ identical over 22 amino acids to a fragment of MBP (Smith et al., 2013). Smith et al. thus propose that MBP and myelinating cells may have evolved before jawed vertebrates.

We note however that the identified fragment is not homolog to MBP. Instead it is homolog to the protein product of the gene-of-the-oligodendrocytelineage (GOLLI) (Figure 1). The function of GOLLI is not well understood. However, unlike MBP, GOLLI is not basic, not incorporated into the myelin sheath, and not essential for myelination (Jacobs et al., 2005; Nawaz et al., 2013). MBP and GOLLI are thus unrelated by sequence and distinct by function. The most likely explanation for the annotation of the golli fragment as $m b p$ is that both occur in the same transcription unit in a range of species (Pribyl et al., 1993; Saavedra et al., 1993; Nawaz et al., 2013). The corresponding mRNAs, many of which encode both GOLLI and MBP, are commonly designated as "MBP" in databases, which also led to the annotation of ESTs as $m b p$ even if they comprise only golli. This indicates that the automated alignment and annotation of nucleotide sequences can introduce systematic errors of designation into the databases. Together, a segment homolog to golli exists in the lamprey genome, but evidence of $m b p$ is lacking.

Other presumed myelin proteins traced in the lamprey genome are not functionally related to myelin at all, despite an equivalent gene ontology (GO) term. For example, MYT1L (myelin transcription factor-1-like), a neuronal transcription factor (Kim et al., 1997), and MAL2 (myelin and lymphocyte protein2), a constituent of synaptic vesicles and hepatocytes (De Marco et al., 2002; Gronborg et al., 2010), bear the term "myelin" in their name simply because of their homology with the founding members of their respective protein families. This suggests that the predictive value of GO terms must be viewed carefully.

On the other hand, the myelin proteins CNP (cyclic nucleotide phosphodiesterase), PMP22 (peripheral myelin protein of $22 \mathrm{kDa}$ ), MAL (myelin and lymphocyte protein), and PLP (proteolipid protein) were previously noted to be evolutionarily older than vertebrates (Mazumder et al., 2002; Gould et al., 2005; Mobius et al., 2008); MPZ (myelin protein zero, $\mathrm{P} 0$ ) is a member of the superfamily of cell adhesion molecules with immunoglobulin-like domains (IgCAM) that exist not only in vertebrates but also in invertebrates. These proteins were thus recruited in ancient vertebrates as myelin constituents from other cellular functions. Accordingly, the identification of corresponding gene segments in lamprey does not help in the identification of the evolutionary emergence of myelinating cells. It is noteworthy that none of these myelin genes is essential for myelination in mice-in contrast 


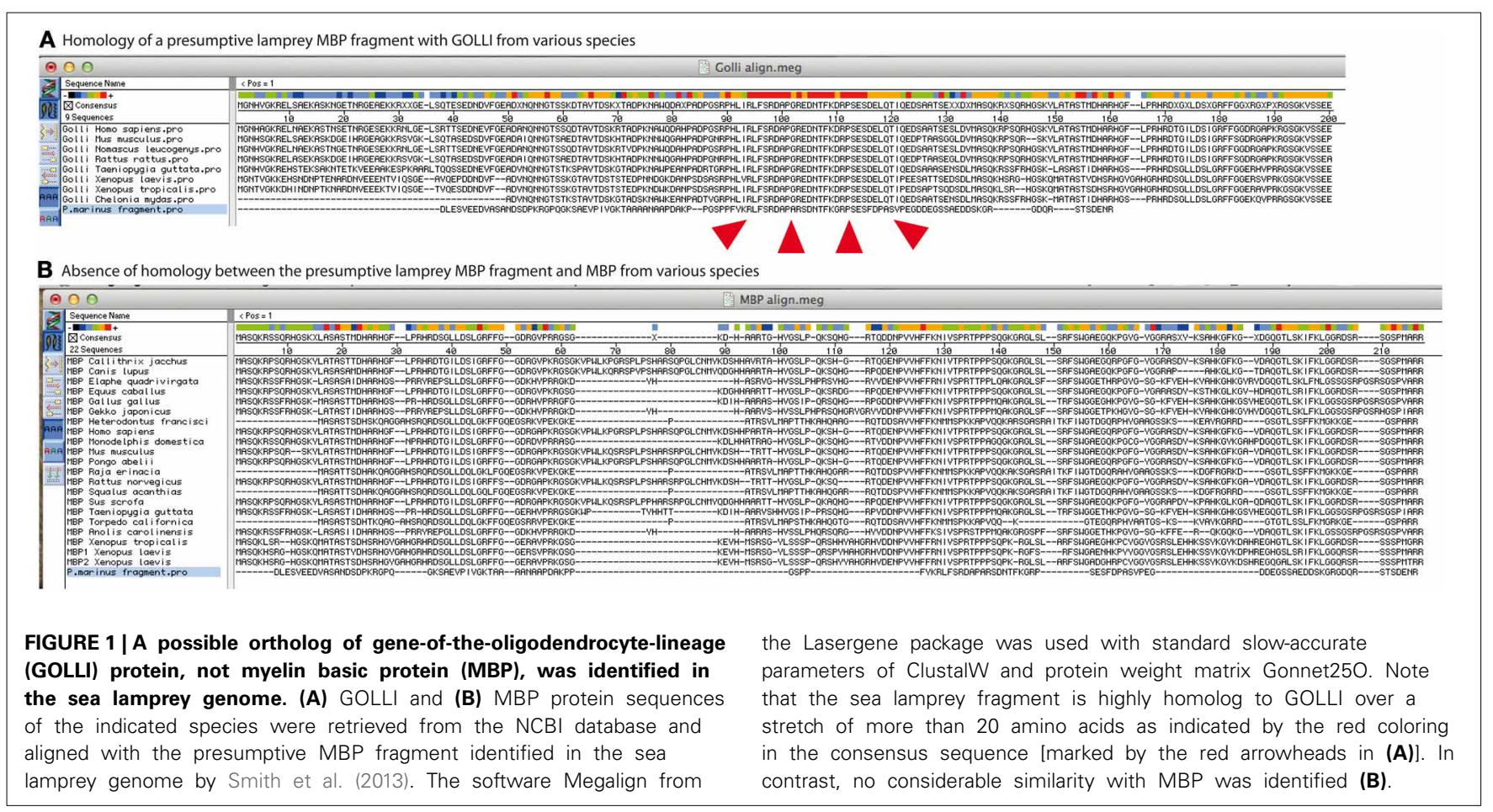

to MBP, which is required for membrane growth and compaction of CNS myelin.

Taken together, the lamprey genome does not provide reason to consider that myelin may have evolved in non-jawed vertebrates. More generally, conclusions from genomic datasets on cellular structures come with the danger of misinterpretations if not carefully considered in conjunction with morphological analyses (Bullock et al., 1984; Schweigreiter et al., 2006; Zalc et al., 2008). Indeed, absence of evidence for MBP in lamprey rather supports the concept that the emergence of myelin was coupled to the emergence of MBP. This innovation of myelin in ancient jawed vertebrates has sped up nerve conduction velocity more than 20 -fold, a prerequisite for the evolution of large-bodied fish with a predatory lifestyle. Without myelin, jawed vertebrates as we know them, including us humans, could not have evolved.

\section{ACKNOWLEDGMENTS}

Hauke B. Werner is supported by the Deutsche Forschungsgemeinschaft (DFG WE 2720/2-1).

\section{REFERENCES}

Bullock, T. H., Moore, J. K., and Fields, R. D. (1984). Evolution of myelin sheaths: both lamprey and hagfish lack myelin. Neurosci. Lett. 48, 145-148. doi: 10.1016/0304-3940(84) 90010-7

De Marco, M. C., Martin-Belmonte, F., Kremer, L., Albar, J. P., Correas, I., Vaerman, J. P. et al. (2002). MAL2, a novel raft protein of the MAL family, is an essential component of the machinery for transcytosis in hepatoma HepG2 cells. J. Cell Biol. 159, 37-44. doi: 10.1083/jcb. 200206033

Gould, R. M., Morrison, H. G., Gilland, E., and Campbell, R. K. (2005). Myelin tetraspan family proteins but no non-tetraspan family proteins are present in the ascidian (Ciona intestinalis) genome. Biol. Bull. 209, 49-66. doi: 10.2307/3593141

Gronborg, M., Pavlos, N. J., Brunk, I., Chua, J. J., Munster-Wandowski, A., Riedel, D., et al. (2010). Quantitative comparison of glutamatergic and GABAergic synaptic vesicles unveils selectivity for few proteins including MAL2, a novel synaptic vesicle protein. J. Neurosci. 30, 2-12. doi: 10.1523/JNEUROSCI.4074-09.2010

Hartline, D. K., and Colman, D. R. (2007). Rapid conduction and the evolution of giant axons and myelinated fibers. Curr. Biol. 17, R29-R35. doi: 10.1016/j.cub.2006.11.042

Jacobs, E. C., Pribyl, T. M., Feng, J. M., Kampf, K., Spreur, V., Campagnoni, C., et al. (2005). Region-specific myelin pathology in mice lacking the golli products of the myelin basic protein gene. J. Neurosci. 25, 7004-7013. doi: 10.1523/JNEUROSCI.028805.2005
Kim, J. G., Armstrong, R. C., V Agoston, D., Robinsky, A., Wiese, C., Nagle, J., et al. (1997). Myelin transcription factor 1 Myt1 of the oligodendrocyte lineage, along with a closely related CCHC zinc finger, is expressed in developing neurons in the mammalian central nervous system. J. Neurosci. Res. 50, 272-290. doi: 10.1002/(SICI) 1097-4547 (19971015)50:2<272::AID-JNR16>3.0.CO;2-A

Mazumder, R., Iyer, L. M., Vasudevan, S., and Aravind, L. (2002). Detection of novel members, structure-function analysis and evolutionary classification of the $2 \mathrm{H}$ phosphoesterase superfamily. Nucleic Acids Res. 30, 5229-5243. doi: 10.1093/nar/ gkf645

Mobius, W., Patzig, J., Nave, K. A., and Werner, H. B. (2008). Phylogeny of proteolipid proteins: divergence, constraints, and the evolution of novel functions in myelination and neuroprotection. Neuron Glia Biol. 4, 111-127. doi: 10.1017/S1740925X0900009X

Nawaz, S., Schweitzer, J., Jahn, O., and Werner, H. B. (2013). Molecular evolution of myelin basic protein, an abundant structural myelin component. Glia 61, 1364-1377. doi: 10.1002/glia.22520

Pribyl, T. M., Campagnoni, C. W., Kampf, K., Kashima, T., Handley, V. W., Mcmahon, J., et al. (1993). The human myelin basic protein gene is included within a 179-kilobase transcription unit: expression in the immune and central nervous systems. Proc. Natl. Acad. Sci. U.S.A. 90, 10695-10699. doi: 10.1073/pnas.90.22.10695

Saavedra, R. A., Lipson, A., Kimbro, K. S., and Ljubetic, C. (1993). The structural complexities of the myelin basic protein gene from mouse are also present in shark. J. Mol. Neurosci. 4, 215-223. doi: 10.1007/BF02821553 
Schweigreiter, R., Roots, B. I., Bandtlow, C. E., and Gould, R. M. (2006). Understanding myelination through studying its evolution. Int. Rev. Neurobiol. 73, 219-273. doi: 10.1016/S0074-7742(06) 73007-0

Smith, J. J., Kuraku, S., Holt, C., Sauka-Spengler, T., Jiang, N., Campbell, M. S., et al. (2013). Sequencing of the sea lamprey (Petromyzon marinus) genome provides insights into vertebrate evolution. Nat. Genet. 45, 415-421, 421e411-e412. doi: $10.1038 /$ ng. 2568
Zalc, B., Goujet, D., and Colman, D. (2008). The origin of the myelination program in vertebrates. Curr. Biol. 18, R511-R512. doi: 10.1016/j.cub. 2008.04.010

Received: 12 August 2013; accepted: 29 October 2013; published online: 15 November 2013.

Citation: Werner HB (2013) Do we have to reconsider the evolutionary emergence of myelin? Front. Cell. Neurosci. 7:217. doi: 10.3389/fncel.2013.00217
This article was submitted to the journal Frontiers in Cellular Neuroscience.

Copyright (C) 2013 Werner. This is an open-access article distributed under the terms of the Creative Commons Attribution License (CC BY). The use, distribution or reproduction in other forums is permitted, provided the original author(s) or licensor are credited and that the original publication in this journal is cited, in accordance with accepted academic practice. No use, distribution or reproduction is permitted which does not comply with these terms. 